\title{
ADSORPTIVE REMOVAL OF FLUORIDE FROM WATER USING BAMBOO DUST AND ITS MODIFIED FORMS: KINETICS AND ISOTHERM STUDY
}

\author{
S. K. Nath ${ }^{1, *}$, K. G. Bhattacharyya ${ }^{2}$ and M. Das ${ }^{3}$ \\ ${ }^{1}$ Department of Chemistry, Gauhati University, Guwahati-781014, (Assam) India \\ ${ }^{2}$ Department of Chemistry, Gauhati University, Guwahati-781014, (Assam) India \\ ${ }^{3}$ Department of Chemistry, University of Science \& Technology Meghalaya, Ri-Bhoi- 793101, \\ (Meghalaya) India \\ *E-mail: sknath.2009@gmail.com
}

\begin{abstract}
In the present study, the interactions of Bamboo Dust and its modified forms are investigated as adsorbents for the removal of $\mathrm{F}^{-}$from aqueous solution. A series of experiments were undertaken in a thermostat water bath batch agitator to assess the effect of different experimental variables such as solution $\mathrm{pH}, \mathrm{F}^{-}$concentration, time and amount of the adsorbents. The adsorption was dependent on the $\mathrm{pH}$ of the solution with $\mathrm{F}^{-}$removal efficiency increased from $\mathrm{pH} 6.0$ to $\mathrm{pH} 7.0$, after which the trend slowly decreases. The adsorption process follows both Freundlich and Langmuir isotherm. The monolayer adsorption capacity obtained from the Langmuir equation increased from $8.01 \mathrm{mg} / \mathrm{g}$ for untreated adsorbents to $25.00 \mathrm{mg} / \mathrm{g}$ for acid-activated adsorbents. The kinetics of the adsorption was also studied for both first and second-order systems and were found to follow first-order kinetics. Keywords: Adsorption, Bamboo Dust, Fluoride, Kinetics, Isotherm.
\end{abstract}

(c) RASĀYAN. All rights reserved

\section{INTRODUCTION}

Fluorine is the first member of the halogen family and is the most electronegative among all the chemical elements in the Periodic Table and so it is chemically highly reactive. Fluorine in the environment is therefore found in combined state as fluorides $\left(\mathrm{F}^{-1}\right)$, the anionic form of fluorine. Fluorine readily reacts with most organic and inorganic substances. When it combines with metals it gives fluorides and remains in the solid-state. In aqueous solution, fluoride can be found as either free anions or in combination with other metals or metalloids. It is found in the form of fluorides in several minerals and many soil rocks. ${ }^{1}$

Fluoride can contaminate ground and surface water by natural processes like weathering and leaching of bedrock with high fluoride content. On the other hand, due to rapid industrial growth for urbanization fluoride concentration is increasing in the environment especially in the aquatic environment. Several fluoride compounds have various industrial applications also e.g. it is widely used in fertilizers, semiconductors, electroplating, glass, steel, aluminum industries, ceramic and nuclear plants which also contribute to fluoride pollution. ${ }^{2,3}$

Fluoride has a dual significance: it plays the role of essential micronutrient for both human and animal bodies in low concentration, on the other hand, beyond the permissible limit of fluoride in drinking-water causes harmful diseases like dental, skeletal and non-skeletal forms of fluorosis. Again if the concentration of fluoride in drinking water is less than the permissible limit, then it may result in problems like dental caries. ${ }^{4}{ }^{5}$ According to BIS standards (IS 10500: 2012) the maximum permissible limit of fluoride in drinking water is $1.5 \mathrm{mg} / \mathrm{L} .6,7$

The major source of fluoride intake is drinking water. High fluoride concentration in drinking water and its impact on human health in many states of India have increased the importance of its removal from water. Many methods for defluoridation of water have been adopted from time to time such as

Rasayan J. Chem., 13(3), 1750-1758(2020)

http://dx.doi.org/10.31788/RJC.2020.1335705

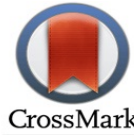


RASĀYAN J. Chem.

Vol. 13 | No. 3 |1750-1758| July - September | 2020

precipitation-coagulation, adsorption, electric defluoridation, ultrafiltration etc. Among them, adsorption is more prominent for the removal of fluoride from drinking water. ${ }^{8}$

The present work aims to develop adsorbents from low cost, easily available plant-based waste materials such as bamboo dust for removal of fluoride from water. To study the fluoride adsorption capacity of these adsorbents, the experimental data obtained under different experimental conditions such as $\mathrm{pH}$, amount of adsorbate and adsorbent, time of the reaction and to obtain different adsorption isotherms, adsorption kinetics and also to determine the order of the reaction.

\section{Reagents}

\section{EXPERIMENTAL}

Reagent grade chemicals, viz., sodium fluoride NaF (Merck, Mumbai, India), HCl(Merck, Mumbai, India), $\mathrm{HNO}_{3}$ (Merck, Mumbai, India), and $\mathrm{H}_{2} \mathrm{SO}_{4}$ (Merck, Mumbai, India) were used. The other chemicals used were also of analytical grade. The $\mathrm{pH}$ of the aqueous solution of $\mathrm{F}^{-}$as prepared was $6.5 \pm 0.1$

\section{Preparation of Stock Solution of Fluoride}

A stock solution of fluoride $(1000 \mathrm{mg} / \mathrm{L})$ was prepared by dissolving $\mathrm{NaF}$ in de-ionized water. The working solution for experiments was freshly prepared by making dilution of the stock solution (1000 $\mathrm{mg} / \mathrm{L})$. Standard acid $\left(0.01 \mathrm{M} \mathrm{HNO}_{3}\right)$ and base solutions $(0.01 \mathrm{M} \mathrm{NaOH})$ were used for $\mathrm{pH}$ adjustments. All other reagents used were of analytical grade.

\section{Preparation of Adsorbent}

To prepare the adsorbents, Bamboo Dust (BD) [B] was collected from the nearest Paper Mill (Nagaon). The collected material was thoroughly washed to remove soluble impurities, dried in an oven at $30-40{ }^{\circ} \mathrm{C}$, ground, and sieved to obtain the fraction between mesh size BIS 50 and 100. Then the adsorbents were activated by treating with $0.5 \mathrm{~N} \mathrm{HCl}, \mathrm{HNO}_{3}$, and $\mathrm{H}_{2} \mathrm{SO}_{4}$ for 5 hours. After activation, the new adsorbents were again washed with de-ionized water to remove the excess acid. Thus we have four types of adsorbents viz., raw $\mathrm{BD}(\mathrm{B}), \mathrm{BD}$ treated with $0.5 \mathrm{~N} \mathrm{HCl}(\mathrm{BH} 1)$, $\mathrm{BD}$ treated with $0.5 \mathrm{~N} \mathrm{HNO}_{3}(\mathrm{BH} 2)$ and $\mathrm{BD}$ treated with $0.5 \mathrm{~N} \mathrm{H}_{2} \mathrm{SO}_{4}(\mathrm{BH} 3)$.

\section{Characterization of the Adsorbents}

The adsorbents prepared were characterized by surface area measurements, determined by methylene blue adsorption method and anion exchange capacity (AEC) determined by the conductometric method. The different functional groups present in the bamboo dust were characterized by FT-IR measurement.

\section{Surface Area}

The determination of surface area (also called as specific surface area) was done by adsorption of Methylene Blue (MB) on the adsorbents. ${ }^{9-12}$ In this method, the adsorbents materials were first hydrated and then they were mixed with different concentrations of a dilute MB solution (25 to $70 \mathrm{mg} / \mathrm{L})$. The mixture was then kept under continuous agitation for 6 hours. The dye concentration $\left(\mathrm{C}_{\mathrm{e}} \mathrm{mg} / \mathrm{L}\right)$, after attaining equilibrium was determined spectrophotometrically, from which the $\mathrm{q}_{\mathrm{e}}(\mathrm{mg} / \mathrm{g})$ value was calculated for each adsorbent. Using Langmuir isotherm:

$$
\mathrm{C}_{\mathrm{e}} / \mathrm{q}_{\mathrm{e}}=\left(1 / \mathrm{bq}_{\mathrm{m}}\right)+\left(1 / \mathrm{q}_{\mathrm{m}}\right) \mathrm{C}_{\mathrm{e}}
$$

The monolayer adsorption capacity, $\mathrm{q}_{\mathrm{m}}$ is calculated from the isotherm plot $\left(\mathrm{C}_{\mathrm{e}} / \mathrm{q}_{\mathrm{e}} \mathrm{vs} . \mathrm{C}_{\mathrm{e}}\right){ }^{13}$ The specific surface area $\left(\mathrm{s}_{\mathrm{g}}\right)$ is calculated using the relation:

$$
\mathrm{s}_{\mathrm{g}}=\mathrm{M}_{\mathrm{f}} \times \mathrm{A}_{\mathrm{m}} \times \mathrm{N}_{\mathrm{A}}
$$

Here, $\mathrm{M}_{\mathrm{f}}=$ number of meq of MB adsorbed per $100 \mathrm{~g}$ which can be obtained from $\mathrm{q}_{\mathrm{m}}, \mathrm{A}_{\mathrm{m}}=$ surface area of $\mathrm{MB}\left(1.30 \times 10^{-18} \mathrm{~m}^{2} /\right.$ molecule $)$, and $\mathrm{N}_{\mathrm{A}}=6.023 \times 10^{20}$ molecules per meq). 
RASĀYAN J. Chem.

Vol. 13 | No. 3 |1750-1758| July - September | 2020

\section{Anion Exchange Capacity}

This method is based on conductometric titration. Here $0.2 \mathrm{~g}$ of the adsorbent was added to $20 \mathrm{~mL}$ of conductivity water. It was titrated conductometrically using standard $\mathrm{AgNO}_{3}$. This titration was repeated using standard $\mathrm{NaCl}$ against the same $\mathrm{AgNO}_{3}$. The conductance starts increasing after the endpoint in both cases. It is then plotted against the volume of the $\mathrm{AgNO}_{3}$ solution used. The equivalence point of the reaction was noted from the plots. The anion exchange capacity (AEC) was calculated using from the difference in volumes of $\mathrm{AgNO}_{3}$ solutions using:

$$
\mathrm{AEC}=\mathrm{NV} / \mathrm{W}
$$

Here $\mathrm{N}=$ strength of the $\mathrm{AgNO}_{3}$ solution in normality and $\mathrm{V}=$ volume required by $\mathrm{W} g$ of the material taken. ${ }^{14}$

\section{FT-IR study}

In the present study, the transmission spectra were obtained between 4000 and $450 \mathrm{~cm}^{-1}$ using the PerkinElmer Spectrum RXI spectrophotometer with $\mathrm{KBr}$ self-supported pellet technique for the determination of the presence of different functional groups.

\section{Adsorption Experiments}

Batch adsorption experiments were conducted by shaking a predetermined amount of the adsorbent with $50 \mathrm{~mL}$ of the known adsorbate concentration in $100 \mathrm{~mL}$ polypropylene Erlenmeyer flasks closed with corks inside a temperature-controlled water bath shaker to study the effects of solution $\mathrm{pH}$, initial fluoride ion concentration and amount of adsorbent. The $\mathrm{pH}$ of the adsorbate solution was carefully adjusted by adding $0.01 \mathrm{~N} \mathrm{NaOH}$ and $0.01 \mathrm{~N} \mathrm{HNO}_{3}$ as required. To study the effect of $\mathrm{pH}$ variation on the adsorption process, the $\mathrm{pH}$ was varied from $3.0-11.0$. At the end of the specified time, the mixture was filtered to remove the adsorbent and the concentration of fluoride remaining unadsorbed was determined using a UV-Visible spectrophotometer (SHIMADZU UV 1800). All other adsorption experiments were carried out at as prepared $\mathrm{pH}$ i.e. at $\mathrm{pH} 6.5 \pm 0.1$.

\section{Adsorption Kinetics}

To study adsorption kinetics, Lagergren's pseudo-first-order and pseudo-second-order kinetic models were used. The equation of Lagergren's pseudo-first-order kinetics can be written as follows:

$$
\ln \left(\mathrm{q}_{\mathrm{e}}-\mathrm{q}_{\mathrm{t}}\right)=\ln \mathrm{q}_{\mathrm{e}}-\mathrm{k}_{1} \mathrm{t}
$$

Here $\mathrm{q}_{\mathrm{e}}$ is the amount of adsorbate adsorbed $\left(\mathrm{mg} \mathrm{g}^{-1}\right)$ per gram of adsorbent at equilibrium and $\mathrm{q}_{\mathrm{t}}$ is the same at any time $t, k_{1}$ is the Lagergren's pseudo-first-order rate constant $\left.\left(\mathrm{min}^{-1}\right)\right)^{5,12,15}$

Pseudo second-order model is represented as:

$$
\mathrm{t} / \mathrm{q}_{\mathrm{t}}=1 / \mathrm{k}_{2} \mathrm{q}_{\mathrm{e}}{ }^{2}+1 / \mathrm{q}_{\mathrm{e}} \cdot \mathrm{t}
$$

Here $\mathrm{q}_{\mathrm{e}}$ and $\mathrm{q}_{\mathrm{t}}$ have the same meaning as mentioned in the previous equation and $\mathrm{k}_{2}$ is the rate constant for the pseudo second-order kinetics $\left(\mathrm{g} \mathrm{mg}^{-1} \mathrm{~min}^{-1}\right) ., 12,15$

\section{Adsorption Isotherm}

To study adsorption isotherm, Freundlich and Langmuir isotherm models were used. The linear form of Freundlich model can be expressed as:

$$
\log \mathrm{q}_{\mathrm{e}}=1 / \mathrm{n} \log \mathrm{C}_{\mathrm{e}}+\log \mathrm{K}_{\mathrm{f}}
$$

Here $\mathrm{C}_{\mathrm{e}}$ is the concentration of adsorbate at equilibrium in $\mathrm{mg} \mathrm{L}^{-1} ; \mathrm{q}_{\mathrm{e}}$ is the amount of adsorbate adsorbed per unit mass of adsorbent in $\mathrm{mg} \mathrm{g}^{-1}, \mathrm{~K}_{\mathrm{f}}$ and $1 / \mathrm{n}$ are Freundlich isotherm coefficients, representing adsorption capacity and adsorption intensity respectively. For favorable adsorption, the value of $1 / \mathrm{n}$ must be less than $1 .^{16,17}$

The linear form of the Langmuir isotherm model can be represented as, given in eqn.-1. 
RASĀYAN J. Chem.

Vol. 13 | No. 3 |1750-1758| July - September | 2020

Here $\mathrm{q}_{\mathrm{m}}\left(\mathrm{mg} \mathrm{g}^{-1}\right)$ and $\mathrm{b}\left(\mathrm{L} \mathrm{mg}^{-1}\right)$ are Langmuir coefficients called monolayer adsorption capacity and Langmuir equilibrium coefficient respectively. ${ }^{13,17}$

\section{Adsorbent Characterization}

Specific Surface Area

The specific surface area $\left(\mathrm{s}_{\mathrm{g}}\right)$ of raw bamboo dust (B) is only $59.50 \mathrm{~m}^{2} \mathrm{~g}^{-1}$, but the value increased to $72.52 \mathrm{~m}^{2} \mathrm{~g}^{-1}$ for BH1, $76.17 \mathrm{~m}^{2} \mathrm{~g}^{-1}$ for BH2, and $84.24 \mathrm{~m}^{2} \mathrm{~g}^{-1}$ for BH3. The report of the specific surface area and the effect of acid treatment on the specific surface area of BD could not be found. The increase in specific surface area for the acid-activated adsorbents is reflected in the results obtained in this work.

\section{Anion Exchange Capacity}

Like a specific surface area, the anion exchange capacity values increases for the acid-activated adsorbents. The value for raw $\mathrm{BD}$ is $2.1 \mathrm{meq} / 100 \mathrm{~g}$ and increases to $2.2 \mathrm{meq} / 100 \mathrm{~g}$ for $\mathrm{BH} 1$ and $\mathrm{BH} 3$ and becomes highest for $\mathrm{BH} 2$. The maximum value is $2.3 \mathrm{meq} / 100 \mathrm{~g}$.

\section{FT-IR study}

FT-IR measurements were done for the determination of different functional groups present before and after acid activation. It was observed that after acid treatment there is no loss of the functional groups only there is a change in \% transmittance. These may be due to the clearance of impurities from the surface of the adsorbent after acid treatment. The different peaks present in the adsorbent are shown in Fig.-1. The different functional groups for raw BD [B] are at $664 \mathrm{~cm}^{-1}$ for S-O stretching, $1038 \mathrm{~cm}^{-1}$ for alc. C-O group, $1112 \mathrm{~cm}^{-1}$ for C-OH, $1260 \mathrm{~cm}^{-1}$ for C-O (Acetate), $1374 \mathrm{~cm}^{-1}$ for C-H bending, $1624 \mathrm{~cm}^{-1}$ for $\mathrm{C}=\mathrm{C}$ stretching, $2360 \mathrm{~cm}^{-1}$ for N-H group, $2922 \mathrm{~cm}^{-1}$ for C-H stretching of $-\mathrm{CH}_{3}$ group and $3422 \mathrm{~cm}^{-1}$ for $\mathrm{O}-\mathrm{H}$ group. It was observed that there is a minimal change in these groups after acid treatment, which indicates that there is no effect on functional groups after acid activation.

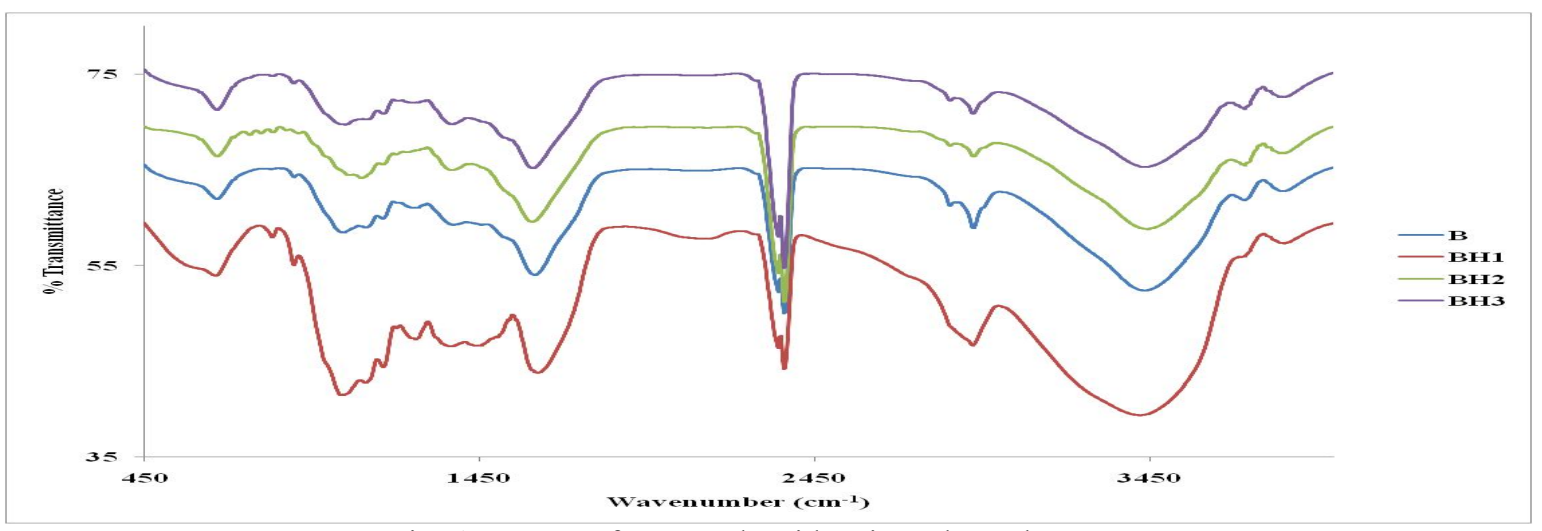

Fig.-1: FT-IR of Raw and Acid activated Bamboo Dust

\section{Effect of Time}

To determine the time at which the equilibrium is attained for the adsorption of fluoride and to study the kinetics of the adsorption, the adsorption process of fluoride on the raw and the acid-treated bamboo dust as a function of time was studied. The plot of time vs. amount of fluoride adsorbed per gram of adsorbent is shown in Fig.2 and it is observed that the adsorption of fluoride on raw and acid-treated BD is fast in the beginning, after which it slowly attained equilibrium. The equilibrium is reached at around 90 min. Ghorai and Pant obtained equilibrium time of after $360 \mathrm{~min}$ for the adsorption of fluoride using activated alumina. ${ }^{18}$

\section{Adsorption Kinetics}

The plot of Lagergren's pseudo-first-order kinetic model at 300K is shown in Fig.-3. From the slope and intercept of the plot, the Lagergren's pseudo-first-order rate constant $\left(\mathrm{k}_{1}\right)$ and $\mathrm{q}_{\mathrm{e}}$ were calculated and the values are given in Table- 1 along with the percentage deviation of experimental $\mathrm{q}_{\mathrm{e}}$ from the calculated $\mathrm{q}_{\mathrm{e}}$ 
RASĀYAN J. Chem.

Vol. 13 | No. 3 |1750-1758| July - September | 2020

and the corresponding regression coefficients of the plots. The calculated equilibrium uptakes are close to the experimental values, which indicate that the rate of adsorption of fluoride on $\mathrm{BD}$ and acid-treated $\mathrm{BD}$ follows pseudo-first-order kinetics. There are many references in which it is observed that adsorption of fluoride follows Lagergren's pseudo-first-order kinetics. ${ }^{19-22}$

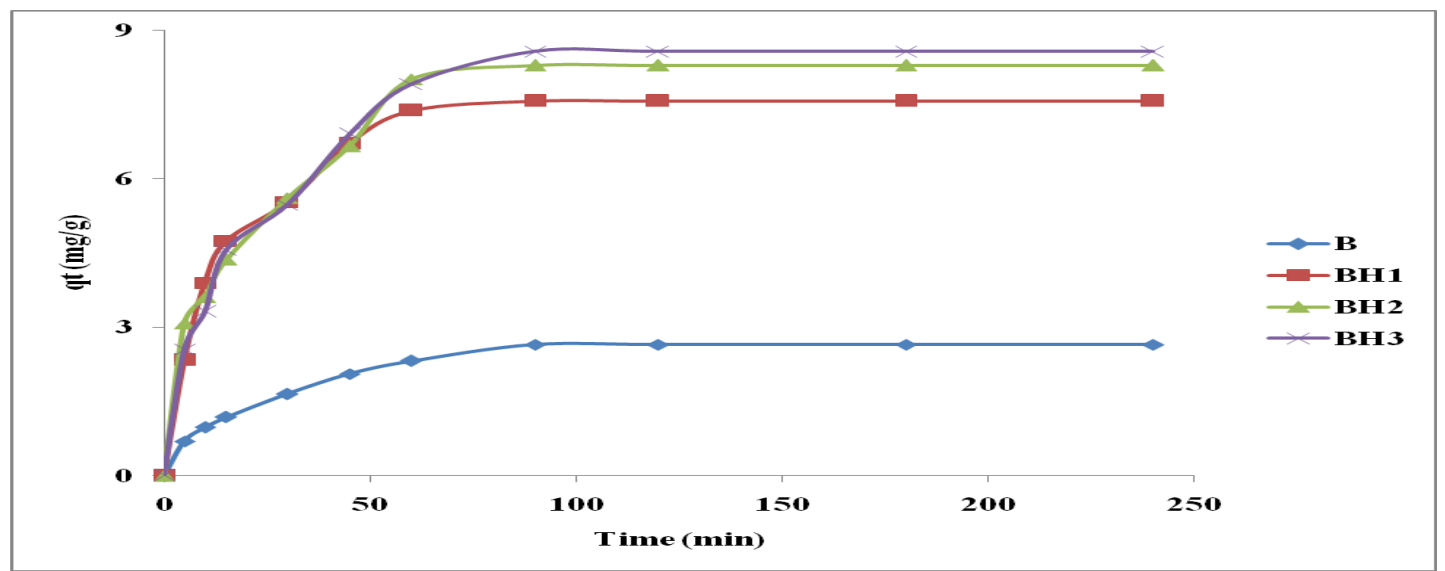

Fig.-2: Effect of Time for Adsorption of Fluoride on Raw and Acid activated Bamboo Dust

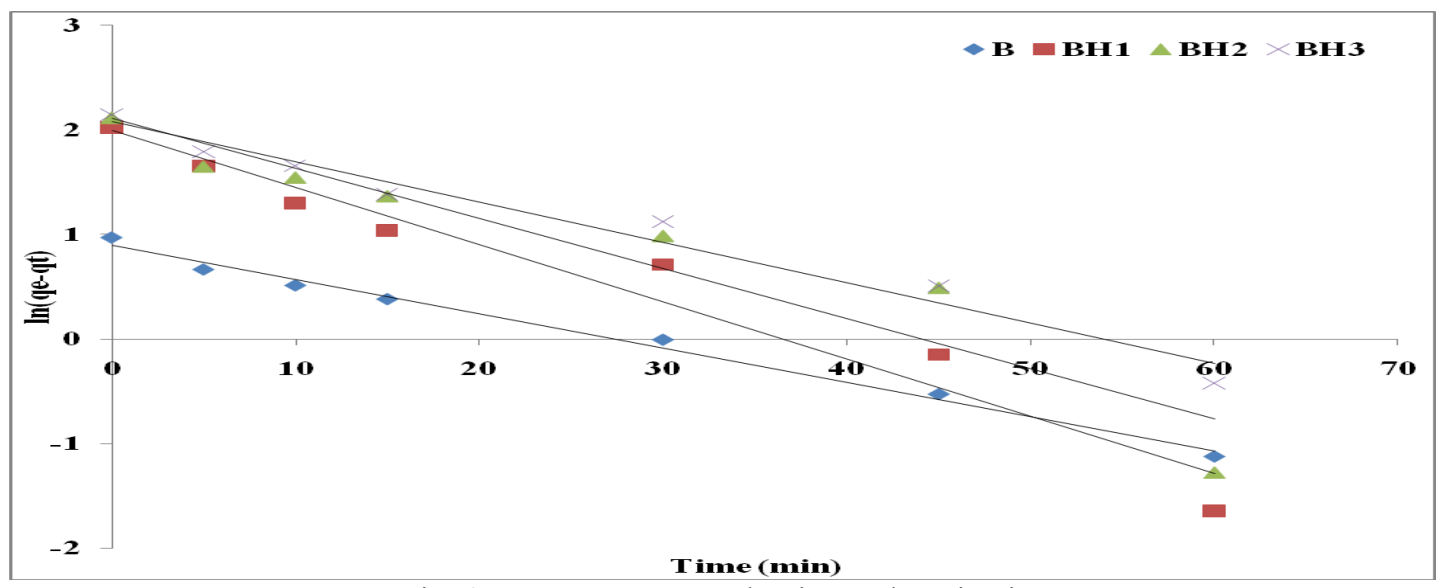

Fig.-3: Lagergren's Pseudo First-order Kinetics

The plots of the pseudo-second-order kinetic model, i.e., $t / \mathrm{q}_{\mathrm{t}}$ versus $\mathrm{t}$ are shown in Fig.-4. The pseudosecond-order rate constant $\left(\mathrm{k}_{2}\right)$ and $\mathrm{q}_{\mathrm{e}}$ calculated from the slope and intercept of the plot are also listed in Table-1 along with the percentage deviation of experimental $\mathrm{q}_{\mathrm{e}}$ from the calculated $\mathrm{q}_{\mathrm{e}}$ and the corresponding regression coefficients of the plots. It was observed that the pseudo-second-order model did not fit well. The calculated equilibrium uptakes are not close to the experimental values, which indicate that the adsorption process does not follow pseudo-second-order kinetics.

\section{Effects of $\mathbf{p H}$}

The $\mathrm{pH}$ of the adsorbate solution plays an important role in controlling the adsorption mechanism of contaminants onto the adsorbate surfaces. In this study, the effects of $\mathrm{pH}$ on the adsorption of fluoride using adsorbents $\mathrm{BD}$ and its acid-treated forms $\left(1 \mathrm{~g} \mathrm{~L}^{-1}\right)$ are investigated by preparing aqueous solutions of fluoride $\left(15 \mathrm{mg} \mathrm{L}^{-1}\right)$ at different $\mathrm{pH}$ values ranging from 3 to 11 at $300 \mathrm{~K}$ for 2 hours. It is observed that the amount of fluoride adsorbed per gram of the adsorbents increases as we increase $\mathrm{pH}$ from 3 to 7 , while an additional increase in the $\mathrm{pH}(>8)$ the adsorption decreases slightly for all the adsorbents (Fig.5). As $\mathrm{pH}$ increases toward 7, the fluoride ion is more compatible than hydroxyl ion in the solution and hence more specific binding, while at basic $\mathrm{pH}$ range the accumulation of hydroxyl ions on the surface results in decreasing adsorption process. ${ }^{21} \mathrm{~A}$ similar result was obtained by using pumice. ${ }^{23}$ 
RASĀYAN J. Chem.

Vol. 13 | No. 3 |1750-1758| July - September | 2020

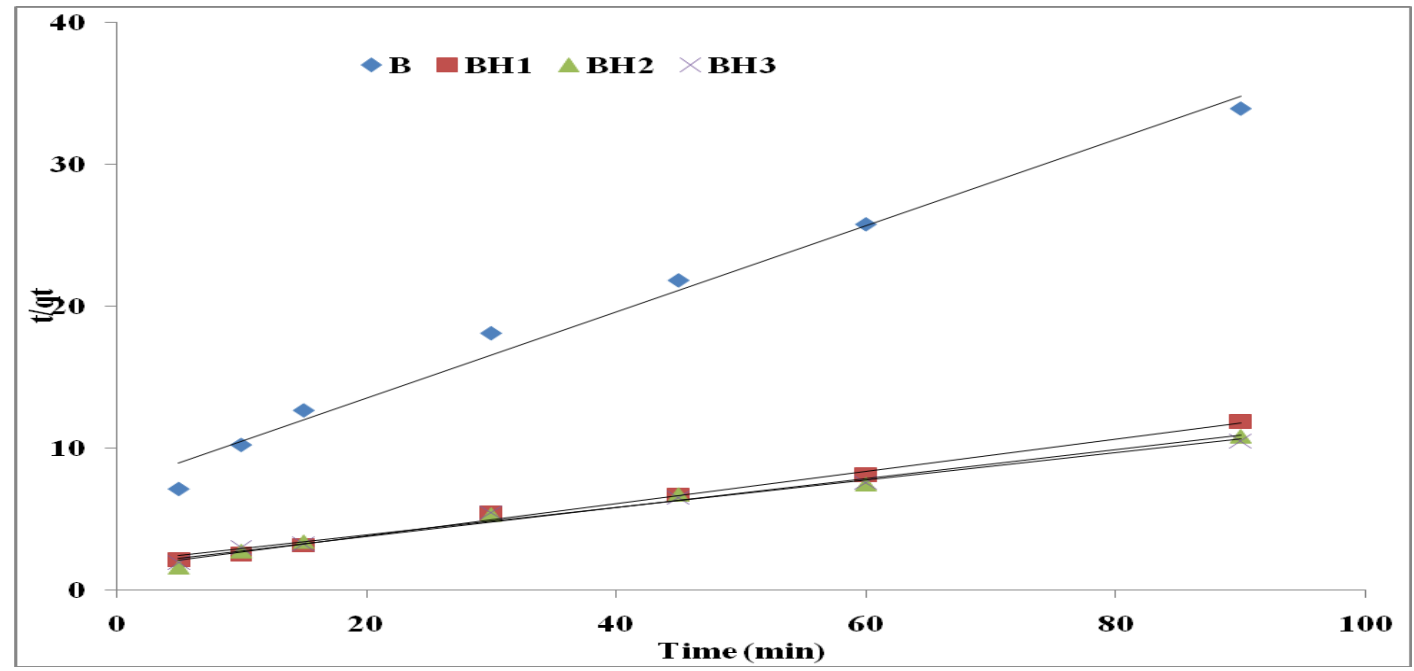

Fig.-4: Pseudo Second-order Kinetics

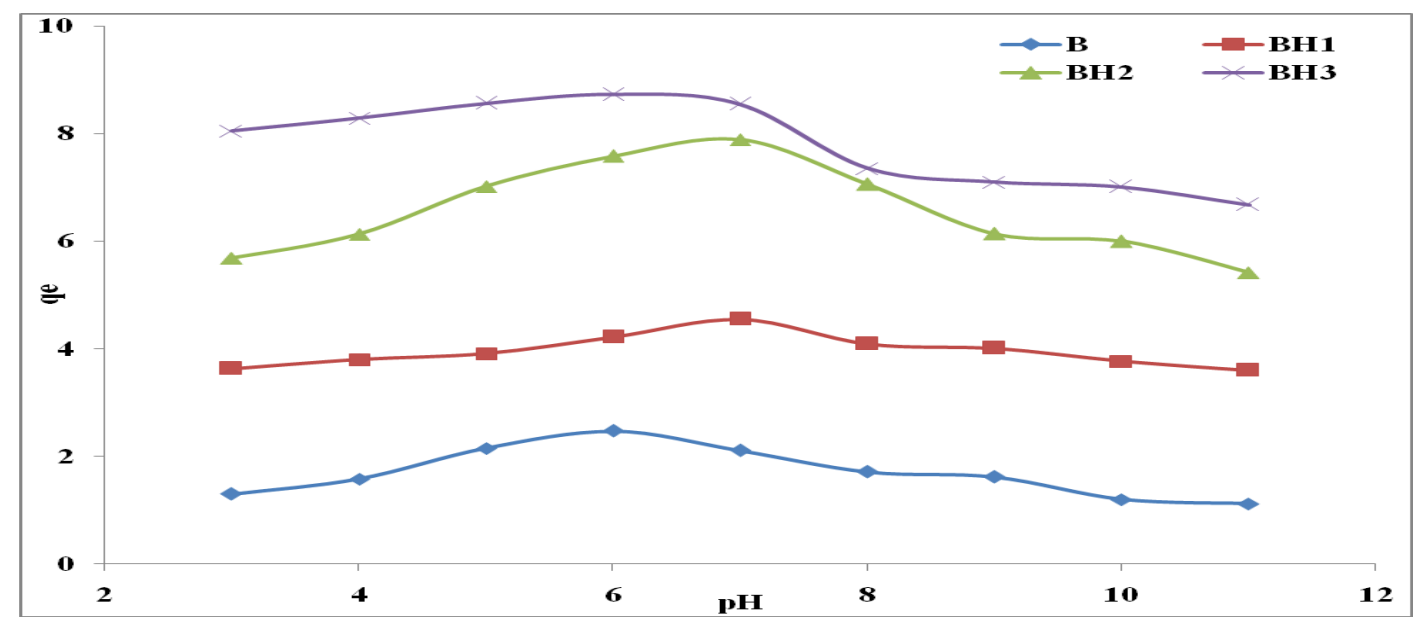

Fig.-5: Influence of $\mathrm{pH}$ on Fluoride Uptake by BD and its Acid activated Forms

Table-1: Parameters of First and Second Order Kinetics

\begin{tabular}{c|c|c|c|c}
\hline & B & BH1 & BH2 & BH3 \\
\hline \multicolumn{5}{c}{ Lagergren's Pseudo First-order Kinetics Value } \\
\hline $\mathrm{k}_{1} \times 10^{2}\left(\mathrm{~min}^{-1}\right)$ & 3.28 & 5.48 & 4.78 & 3.87 \\
\hline Deviation $(\%)$ & 7.18 & 2.72 & 0.56 & 6.22 \\
\hline$(+) \mathrm{r}$ & 1.00 & 0.98 & 0.95 & 0.99 \\
\hline \multicolumn{5}{c}{ Pseudo Second Order Kinetics Value } \\
\hline $\mathrm{k}_{2} \times 10^{3}\left(\mathrm{~g} \mathrm{mg}^{-1} \mathrm{~min}^{-1}\right)$ & 12.40 & 8.31 & 6.10 & 4.80 \\
\hline Deviation $(\%)$ & -24.00 & -15.83 & -17.46 & -20.56 \\
\hline$(+) \mathrm{r}$ & 0.99 & 1.00 & 0.99 & 0.99 \\
\hline
\end{tabular}

Effects of Adsorbate Concentration and Isotherm Study

To study the effect of adsorbate concentration the initial concentration of fluoride is varied from 2.5 to 20 $\mathrm{mg} \mathrm{L} \mathrm{L}^{-1}$ at a constant adsorbent dose of $1 \mathrm{~g} \mathrm{~L}^{-1}$, the amount of fluoride adsorbed per gram of the adsorbent at equilibrium ( $\mathrm{q}_{\mathrm{e}}$ ) increases (Fig.-6) as expected from 0.56 to $2.72 \mathrm{mg} \mathrm{g}^{-1}$ for B, from 1.50 to $8.43 \mathrm{mg} \mathrm{g}^{-1}$ for $\mathrm{BH} 1$, from 1.62 to $8.87 \mathrm{mg} \mathrm{g}^{-1}$ for $\mathrm{BH} 2$, and from 1.67 to $9.03 \mathrm{mg} \mathrm{g}^{-1}$ for $\mathrm{BH} 3$. A higher concentration of fluoride means there will be more fluoride ions per unit volume that will collide with the adsorbent surface and also amongst themselves while trying to get adsorbed on the adsorbent surface. This reduces the effective number of adsorptive collisions and therefore, adsorption decreases with increasing concentration. ${ }^{24}$ 
RASĀYAN J. Chem.

Vol. 13 | No. 3 |1750-1758| July - September | 2020

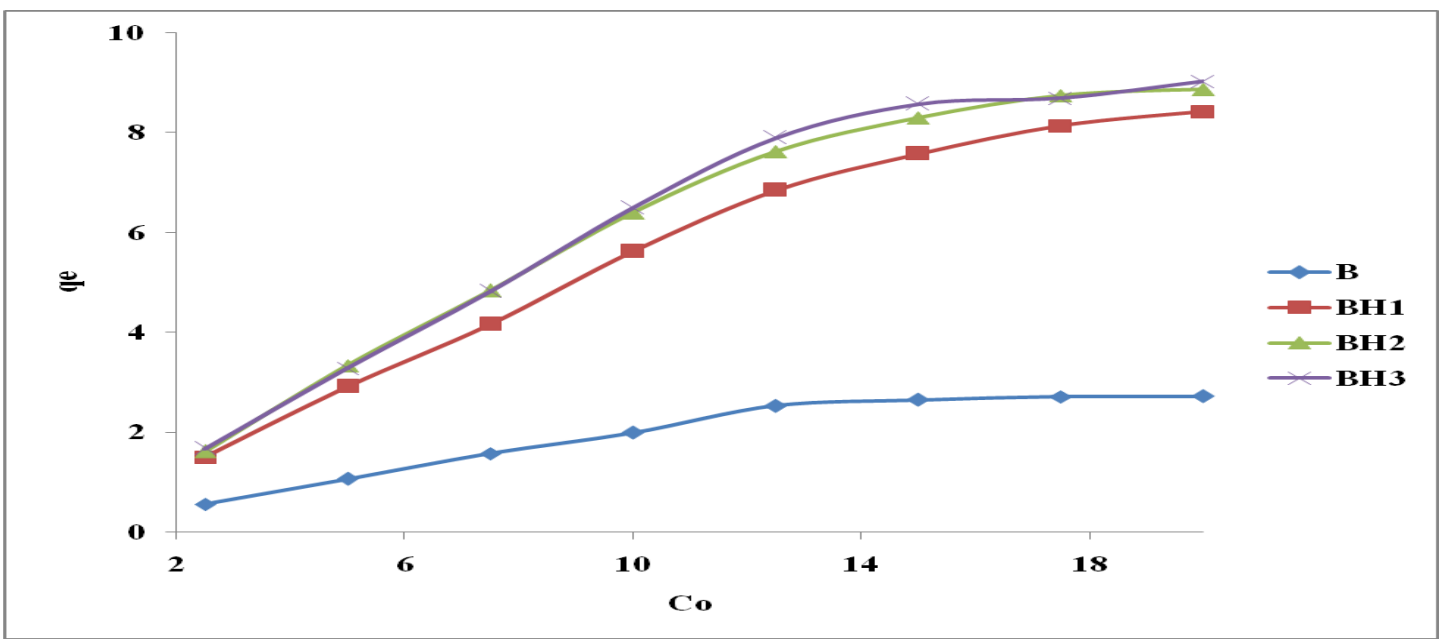

Fig.-6: Effects of Fluoride Concentration for Adsorption on $1 \mathrm{~g} / \mathrm{L} \mathrm{BD}$ and its Modified Forms at $300 \mathrm{~K}$ (pH 6.5, Interaction Time $120 \mathrm{~min}$ )

The Freundlich isotherm plots (Fig.-7) yields good linearity ( $\mathrm{r} \sim+0.96$ to +0.98$)$. The adsorption intensity is given by the Freundlich coefficient ' $1 / \mathrm{n}$ ' obtained from the plots are $0.76,0.73,0.67$ and 0.67 for B, $\mathrm{BH} 1, \mathrm{BH} 2$ and $\mathrm{BH} 3$ respectively, and as the values of adsorption intensity, $1 / \mathrm{n}<1$, which indicates

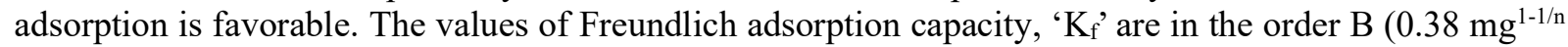
$\left.\mathrm{L}^{1 / n} \mathrm{~g}^{-1}\right)<$ BH1 $\left(1.69 \mathrm{mg}^{1-1 / n} \mathrm{~L}^{1 / n} \mathrm{~g}^{-1}\right)<$ BH2 $\left(2.25 \mathrm{mg}^{1-1 / n} \mathrm{~L}^{1 / n} \mathrm{~g}^{-1}\right)<\mathrm{BH} 3\left(2.31 \mathrm{mg}^{1-1 / n} \mathrm{~L}^{1 / n} \mathrm{~g}^{-1}\right) . \quad$ It $\quad$ is observed from the experimental data that the adsorbents show more adsorption capacity for acid-activated adsorbents than the raw adsorbent. This is reflective of the increased surface area of the adsorbents after acid activation. ${ }^{19}$

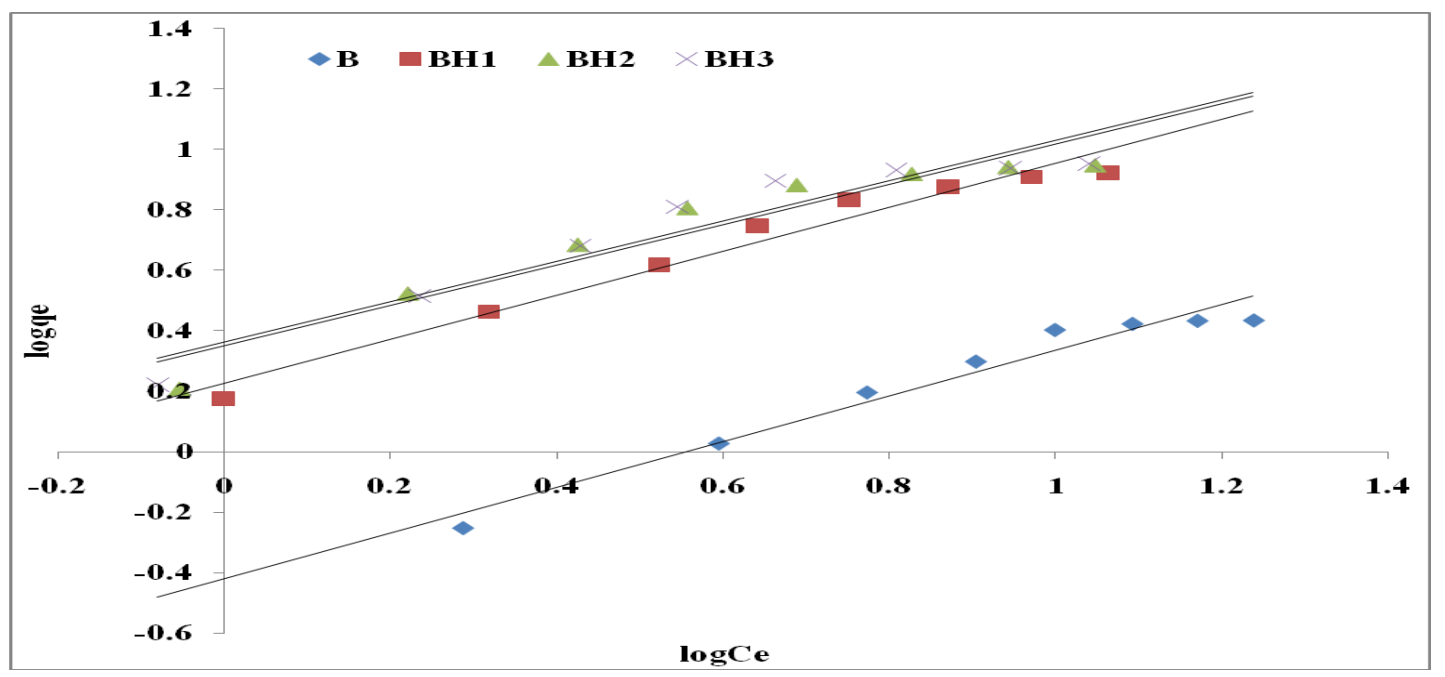

Fig.-7: Freundlich Isotherms for Adsorption of Fluoride on BD and its Modified Forms at $300 \mathrm{~K}(\mathrm{pH}$ 6.5, Interaction Time $120 \mathrm{~min})$

The Langmuir isotherm plots (Fig. -8 ) shows good linearity also with $\mathrm{r} \sim+0.99$ to +1.00 . The Langmuir equilibrium coefficient ' $b$ ' values are in the range of $0.04-0.10 \mathrm{~L} \mathrm{~g}^{-1}$. The monolayer adsorption capacity obtained from Langmuir, ' $\mathrm{q}_{\mathrm{m}}$ ' has values of $8.01 \mathrm{mg} \mathrm{g}^{-1}$ (B), $19.45 \mathrm{mg} \mathrm{g}^{-1}$ (BH1), $25.00 \mathrm{mg} \mathrm{g}^{-1}$ (BH2) and $21.82 \mathrm{mg} \mathrm{g}^{-1}$ (BH3). It is observed that the monolayer adsorption capacity increases for the adsorbents after acid activation. It might be because the active sites for fluoride uptake on the adsorbent surface constitute a small fraction of the total surface area. The binding energy constant, i.e. the ' $b$ ' values reveal that the active surface area for all adsorbents is similar..$^{20,25}$ 
RASĀYAN J. Chem.

Vol. 13 | No. 3 |1750-1758| July - September | 2020

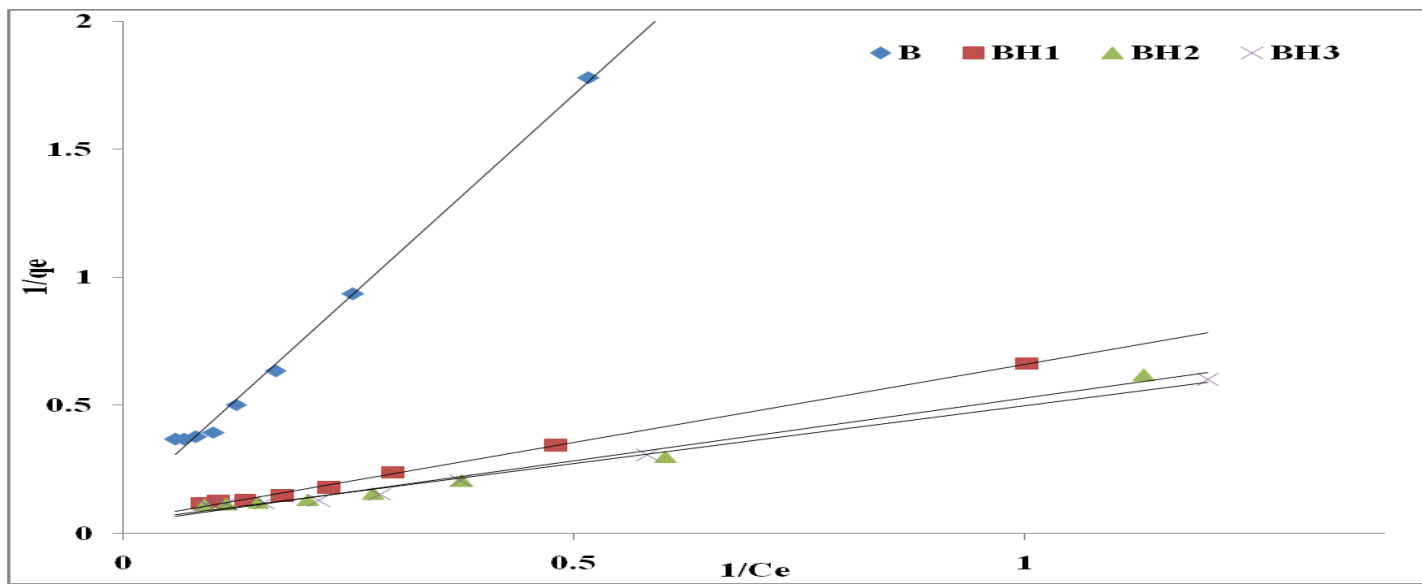

Fig.-8: Langmuir Isotherms for Adsorption of Fluoride on BD and its Modified forms at $300 \mathrm{~K}$ (pH 6.5, Interaction

\section{Effects of Adsorbent Amount}

Time $120 \mathrm{~min}$ )

To study the effect of adsorbent amount, the amount of the adsorbent is increased from 1 to $3 \mathrm{~g} \mathrm{~L}^{-1}$ (Fluoride ion concentration was $15 \mathrm{mg} \mathrm{L}^{-1}$ ), the amount of fluoride adsorbed per gram of the adsorbent decreases from 2.65 to $1.51 \mathrm{mg} \mathrm{g}^{-1}, 7.58$ to $2.84 \mathrm{mg} \mathrm{g}^{-1}, 8.30$ to $3.10 \mathrm{mg} \mathrm{g}^{-1}$ and 8.58 to $3.45 \mathrm{mg} \mathrm{g}^{-1}$ for B, $\mathrm{BH} 1, \mathrm{BH} 2$ and $\mathrm{BH} 3$ respectively (Fig.-9). This is obvious as the increase in adsorbent amount leads to particle aggregation, which results in a decrease in the total surface area. Also on increasing the adsorbent amount leads to the increase in diffusion path length (as the total surface area decreases). The above two reasons are the explanations for the decrease in amount adsorbed per unit mass on the increasing amount of adsorbent ${ }^{26}$.

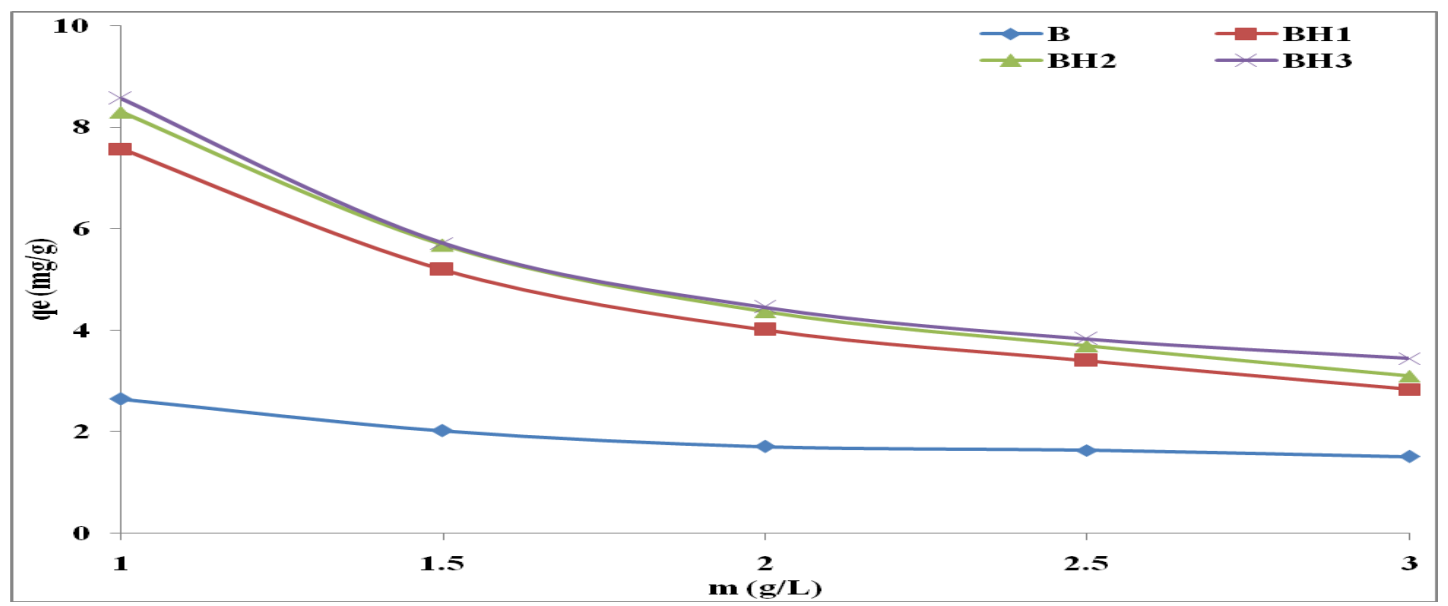

Fig.-9: Influence of Adsorbent Amount on Adsorption of Fluoride on BD and its Modified forms at $300 \mathrm{~K}$ (Initial Fluoride Concentration $15 \mathrm{mg} / \mathrm{L}, \mathrm{pH}$ 6.5, Interaction Time $120 \mathrm{~min}$ )

\section{CONCLUSION}

From the above discussion, it can be concluded that bamboo dust and its acid-activated forms are effective adsorbents for the removal of fluoride from water. The amount of fluoride adsorbed per unit mass of the adsorbent increases for the acid-activated adsorbents. Acid activation of the adsorbents results in increases in the adsorption capacity compared to the raw adsorbent, as the surface area and anion exchange capacity increase after acid activation. It is observed that $\mathrm{pH}$ has significant influences on adsorption and the adsorbents have good adsorption capacity in the neutral $\mathrm{pH}$ range and increase on acid activation. To predict the adsorption kinetics, Lagergren's pseudo-first-order and pseudo-second-order kinetic models were applied to the experimental data and observed that the adsorption of fluoride follows first-order kinetics. The adsorption process obeys Langmuir as well as Freundlich isotherms at lower 
RASĀYAN J. Chem.

Vol. 13 | No. 3 |1750-1758| July - September | 2020

adsorbent dose. Thus, bamboo dust and especially acid-activated bamboo dust can be used as an efficient and economic adsorbent for the removal of fluoride.

\section{REFERENCES}

1. M. Kishore and Y. Hanumantharao, Rasayan Journal of Chemistry, 3(2), 341(2010)

2. E. Oguz, Journal of Hazardous Materials, B117, 227(2005), DOI:10.1016/j.jhazmat.2004.09.020

3. B. S. Meena and N. Bhargava, Rasayan Journal of Chemistry, 5(4), 438(2012)

4. S. Dey and B. Giri, Medical \& Clinical Reviews, 2(1:2), 1(2016),DOI:10.21767/2471-299X.1000011

5. P. Cai, H. Zheng, C. Wang, H. Ma, J. Hu, Y. Pu and P. Liang, Journal of Hazardous Materials, 213214, 100(2012), DOI:10.1016/j.jhazmat.2012.01.069

6. L. Lv, J. He, M. Wei and X. Duan, Industrial and Engineering Chemistry Research, 45, 8623(2006), DOI: $10.1021 / \mathrm{ie} 050363 \mathrm{~d}$

7. S. Tamrakar, R. Verma, S. K. Sar and C. Verma, Rasayan Journal of Chemistry, 12(2), 455(2019), DOI: $10.31788 /$ RJC.2019.1225106

8. Meenakshi, and R.C. Maheshwari, Journal of Hazardous Materials, B137, 456(2006). DOI:10.1016/j.jhazmat.2006.02.024

9. J. J. Kipling and R. B. Wilson, Journal of Applied Chemistry, 10, 109(1960)

10. P. T. Hang and G.W. Brindley, Clays and Clay Minerals, 18, 203(1970)

11. R. Aringhieri, G. Pardini, M. Gispert and A. Sole, Agrochimica, 36, 2(1992)

12. Y. A. B. Neolaka, E. B. S. Kalla, G. A. Malelak, N. K. Rukman G. Supriyanto and N. N. T. Puspaningsih, Rasayan Journal of Chemistry, 11(2), 494(2018), DOI:10.7324/RJC.2018.1121994

13. I. Langmuir, Journal of the American Chemical Society 38, 2221(1916), DOI:10.1021/ja02268a002

14. T. S. Anirudhan and S. Jalajamony, Journal of Environmental Management, 91, 2201(2010), DOI: $10.1016 /$ j.jenvman.2010.05.019

15. V. Sivasankar, S. Rajkumar, S. Murugesh and A. Darchen, Journal of Hazardous Materials, 225226, 164(2012), DOI:10.1016/j.jhazmat.2012.05.015

16. Freundlich H.M.F., Over the adsorption in solution, The Journal of Physical Chemistry, 57, 385(1906)

17. N. C. Joshi and V. Bahuguna, Rasayan Journal of Chemistry, 11(1), 142(2018), DOI: 10.7324/RJC.2018.1112008

18. S. Ghorai and K.K. Pant, Separation and Purification Technology, 42, 265(2005), DOI: 10.1016/j.seppur.2004.09.001

19. F. Fufa, E. Alemayehu and B. Deboch, Journal of Environmental and Occupational Science, 3(2), 71 (2014), DOI:10.5455/jeos.20140314041743

20. M. Islam and R.K. Patel, Journal of Hazardous Materials, 143, 303(2007), DOI: 10.1016/j.jhazmat.2006.09.030

21. S. Mandal, S. Tripathy, T. Padhi, M. K. Sahu and R. K. Patel, Journal of Environmental Sciences, 25(5), 993(2013), DOI:10.1016/S1001-0742(12)60146-6

22. B. Kebede, A. Beyene, F. Fufa, M. Megersa and M. Behm, Applied water science, (2014), DOI: 10.1007/s13201-014-0210-x

23. M. Malakootian, M. Moosazadeh, N. Yousefi and A. Fatehizadeh, African Journal of Environmental Science and Technology, 5(4), 299(2011)

24. H. Ucun, Y. K. Bayhan, Y. Kaya, A. Cakici and O. F. Algur, Desalination, 154, 233(2003), DOI: 10.1016/S0011-9164(03)80038-3

25. T. L. Tan, P. A/P Krusnamurthy, H. Nakajima and S. A. Rashid, RSC Advances, 10, 18740(2020), DOI: $10.1039 / \mathrm{d} 0 \mathrm{ra} 01268 \mathrm{~h}$

26. B. Yu, Y. Zhang, A. Shukla, S. S. Shukla and K. L. Dorris, Journal of Hazardous Materials B80, 33(2000), DOI:10.1016/s0304-3894(00)00278-8

[RJC-5705/2020] 